\title{
A WEB PLATFORM FOR CRISIS MANAGEMENT BASED ON VOLUNTARY DATA AND FREE TOOLS IN CASE OF NATURAL DISASTER
}

\author{
Hafid Mohammed Amine ${ }^{1}$, Bouhadjar Meguenni ${ }^{2}$ \\ ${ }^{1}$ Geomatics Laboratory, Center of space techniques, Arzew Oran, Algeria, hafid92002@yahoo.fr \\ ${ }^{2}$ Geomatics Laboratory, Center of space techniques, Arzew Oran, Algeria, meguennib@ hotmail.com
}

Commission VI, WG VI/4

KEY WORDS: Natural Disaster, OpenStreetMap, spatial database, Web Platform

\begin{abstract}
:
Disasters often result serious human and material damage. In the last two decades, Algeria has recorded over a dozen natural disasters between earthquakes and floods that hit the country, especially between 1994 and 2009, causing 3457 deaths and extensive damage estimated at about 211 million dollars, including Boumerdes City region following the earthquake on the May 21 st, 2003.

An effective intervention of emergency based on good management of resources such as road, can limit the damage in practice. The road network can be easily damaged by a natural disaster which makes it partially or completely unusable. Also, it would be crucial to quickly map the most affected areas and associate them with a list of the necessary aids, or even indicate the places probably in danger to ensure the safety of the nearby population.

Currently, web mapping and especially voluntary web mapping (such as the famous OpenStreetMap) are presented as a key tool for the management of crisis response teams, thanks to their mobility and simplicity for the wider public, the latter can play a vital role in creating and sharing real-time data from disaster areas to better manage emergency services. A web platform will allow the contribution of anyone wishing to provide support from its location using mobile devices, and enrich the crisis cells with the largest amount of geospatial information.

Our work consists of implementing a web platform based on free tools and existing data. This platform will be accessible in case of natural disaster by everyone in order to supply its database. A global methodology for structuring and the implementing will be presented and discussed.
\end{abstract}

\section{INTRODUCTION}

\subsection{What to do during a natural disaster?}

When a natural disaster occurs, no one knows what to do first, how to react, where to go, including how to get safe long before rescuing. By the time the authorities react and set up structures, precious hours can go on and cost the lives of dozens of people. This timeframe could simply be canceled using an application that would connect citizens and authorities and transmit information observed in real time on both sides.

At present, maps and cartographic landmarks of a disaster area are not transmitted directly to citizens, institutions and to rescue teams because of delays in implementation (due to the need for a drone for example) (Bretmaps 2019) . The idea is to improve mapping procedures for disaster-affected areas, and to improve the timeliness and availability of data to affected people.

\subsection{Databases and GIS for natural disasters}

Databases have always existed. Currently, they become computerized, so theoretically more accessible, even if it causes new difficulties. Concerning natural disasters, we must be interested in many phenomena affecting the same space, whether these phenomena are spatially or historically different. The establishment of databases facilitates access to this information and thus helps management and decision-making through analysis and diffusion of data, it's the concept of information systems.
Conventionally, information systems must perform the following functions:

- produce legal or quasi-legal information required by the socioeconomic environment;

- initiate programmed actions following the appearance of some events (this is the result of the analyzes);

- provide the various contributors with relevant information to enable them to react to the demands they are subjected to;

- enable communication of information between contributors to ensure proper coordination of activities (Yannick 2006).

The Geographic Information Systems (GIS) are systems (software) used in: Acquisition; Archiving, Analyzing and Displaying data, these four phases process data by abstracting a number of real-world details. Therefore, it is relevant to build a Space Reference Information System (SIRS) for the management of natural disasters given their geographical characteristics, and this will answer a number of questions. 


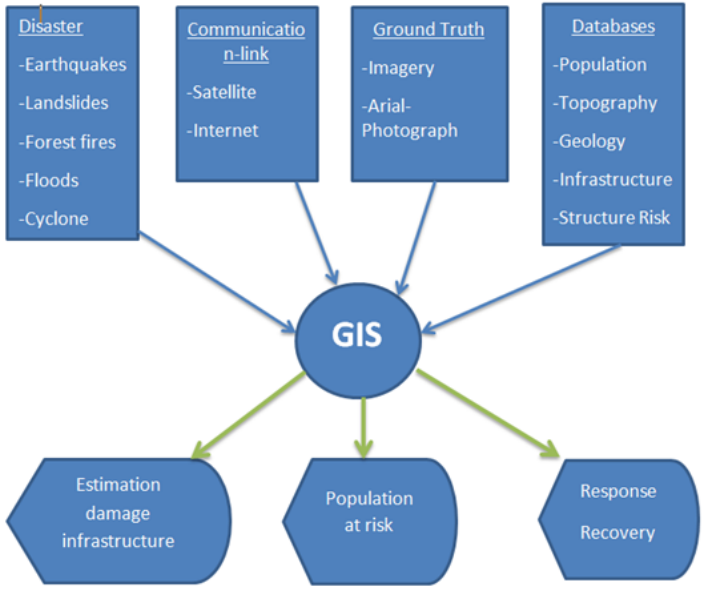

Figure 1. Figure GIS for Disaster Management

\section{VOLUNTARY GEOGRAPHIC INFORMATION (VGI):}

\subsection{Principle}

Voluntary Geographic Information (VGI), which refers to providing geospatial content by ordinary people, has become an established practice in the GIS and geographic areas. One of the most convincing examples of VGI is Wikimapia, which adapts some of the procedures that have been so successful in creating the Wikipedia encyclopedia and applies them to creating a geographic directory. Anyone with an Internet connection can select an area on the Earth and provide a description, including links to other sources. Any person can edit entries, and volunteer evaluators monitor the results and check for accuracy and meaning.

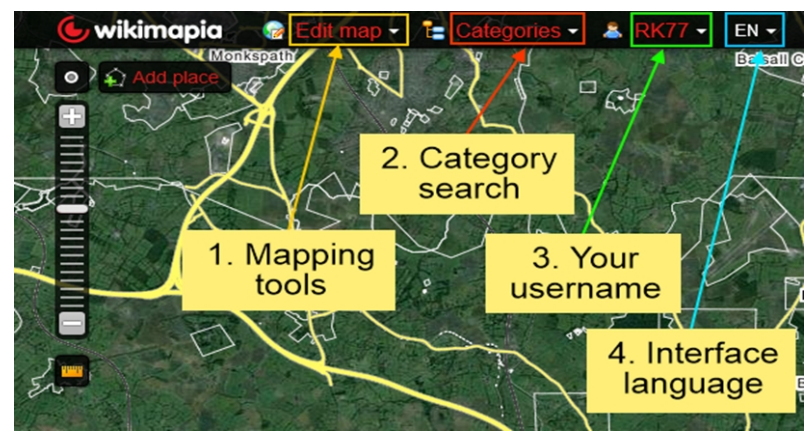

Figure 2. Figure Wikimapia Interface

Another type of VGI is the data shared in social networking services like Facebook, Tweeter or Flickr. We can explore such information by searching words (recent) for example: flood, and then we have to compare results to other information.

\subsection{OpenSteetMap OSM}

Started in 2004 OpenStreetMap is today the most popular VGI project. So far, it has attracted about two and a half million contributors and has produced the world's largest and most diverse geospatial database. The growing success of the OSM is largely due to an open data license that allows everyone to copy, distribute, transmit and adapt data, with condition that credit is given to OSM and its contributors.

\subsection{Can we trust OSM data in sensitive areas}

According to the study conducted by Arsanjani (Arsanjani 2011), a total of 346 contributors contributed 15,350 road segments, which are in total 2,624 km road networks within the study site. Once the datasets were prepared, the data quality analysis was applied in order to initially evaluate aspects of data quality criteria and subsequently rank OSM contributors according to the quantity and quality of their contributions. As such, positional accuracy, temporal accuracy, logical accuracy, semantic accuracy for each individual contributor is computed and discussed.

\begin{tabular}{|l|l|}
\hline Contributors category & Percentage \% \\
\hline beginner & $74.3 \%$ \\
regular & $16.5 \%$ \\
intermediate & $6.1 \%$ \\
expert & $2.9 \%$ \\
professional & $0.3 \%$ \\
\hline
\end{tabular}

Table 1. Pattern of different OSM contributors according to the quality of their contributions

The author suggests in his conclusion that the contributor should be taken into account in the assessment of the data and this depends on the field of use of the shared data. The study allows opening the eye on the quality of OSM data as soon as these data will be used in sensitive areas, for example: the safety of the road network and especially in case of natural disaster.

In our work we can solve this problem by the redundancy of the data coming from several contributors, also we can trust the authoritarian institutes for the assessment and the confirmation of the information shared.

There are other studies on the OSM: Zielstrand zipf (2010) observed that the OSM contained more data in large cities and lower coverage in rural areas, and for accuracy, HAkay (2010a) has found that is about 06 meters (reasonable) but this distance has changed from one region to another.

These last two studies cited above encourages us to trust the OSM data, and at least we can use OSM data as a background support for the rest of our work, and then we will be able to choose locations on it.

\section{DISASTER MANAGEMENT}

Two types of disaster management can be distinguished: disaster management at the time of happening (in real time), and post-disaster management.

The second type consists in analyzing the disaster and its consequences to be able to give answers with regard to the prevention and planning, the census of the damage and the attribution of the aids and refunds.

while the first type which is the subject of our research is to accompany the rescue services in their efforts to reduce the number of victims as well as the damage, this is done by providing the maximum of information on the place of the disaster by people stuck in it, or people from outside who know the area. 


\subsection{The significance of time in the event of a natural disaster}

The speed of arrival of a disaster can be fast (sudden): little warning or without warning, minimum time to prepare. For example, an earthquake, tsunami, cyclone, volcano, etc.; or a slow arrival: slow to develop; it second level is the emergency situation; and the third level is a disaster situation. For example, drought, epidemic, etc.

Faced with the sudden and huge needs of disaster victims, the time to save lives is measured in minutes and hours, not days. It should not be forgotten that there is already a time for collecting information, and extra time for reflection and decision-making.

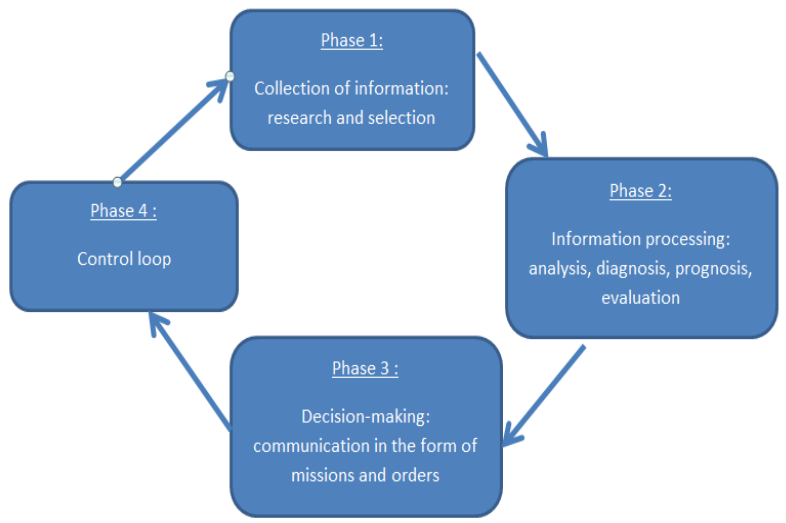

Figure 3. Figure Steps in the decision-making process of the Emergency Operations Commander in a rescue operation situation (LACROIX 2014)

\subsection{Consequences of a disaster on the region and the environment}

Adding to loss of life, the following list identifies some of the undesirable impacts on the region and the environment:

- Deterioration of infrastructure

- Loss of telecommunications

- Floods

- Landslides

- Electricity Cuts

- Water problems

- Damage in agriculture

- Housing Loss / damaged home

- Damage to the country's interior and coastal environment

- Disruption of level and lifestyle, etc.

To deal with these problems caused by a natural disaster, the intervention and management efforts must focus on the following objectives:

- Ensure the survival of as many as possible of victims; keep them in the best possible health in the circumstances they are in. - Restore self-sufficiency and essential services as quickly as possible for all the population, with special attention for those with the most needs: the most vulnerable and the least privileged.

- Repair and restore damaged infrastructure and restore viable economic activities. Do this in a way that pursues long-term development goals and reduces vulnerability to future dangers of potential deterioration.

- In the event of displacement of the population (following any type of disaster), the objective is to find durable solutions as quickly as possible, while at the same time ensuring the necessary protection and assistance.

\section{METHODOGIE OF THE WORK}

The idea is to allow a whole user at the time of the crisis (and even after) to provide information via a web platform ( $\mathrm{pc}$, tablet, and smartphone). The user may be an organization, a person familiar with the disaster area, an on-site eyewitness, or a blocked victim who needs help. The information (contribution) will be stored in an online database, and shared directly.

The contribution is in the form of a point created on a map (we chose OSM map), and at each point we associate attributes: need help, road blocked, water level that increases, danger zone...etc. and at any time, everyone can access the website and observe the information shared and represented by symbols describing the point and with the possibility to display the attributes that it contains.

This kind of information is very helpful for analyzing and making decisions to save lives or help keep the victim healthy until help arrives.

\subsection{Examples of similar platforms}

4.1.1 CATastrophes NATurelles.net (catnat.net): a permanent observatory of natural disasters and natural risks, it offers services to the subscriber by different ways (sms, mail ...), we can find as information: alert and prevention, statistics, databases, permanent news.

This platform collects the information of several entities, the database lists nearly 15,000 natural-related damaging events worldwide since 1 January 2001 and is constantly updated, making it a true real-time statistical observatory of natural disasters around the world. Each event is characterized by 27 parameters (temporal, geographical, phenomenological (hazard / danger / sub-danger), human and material severity, cost...). (catnat 2019)

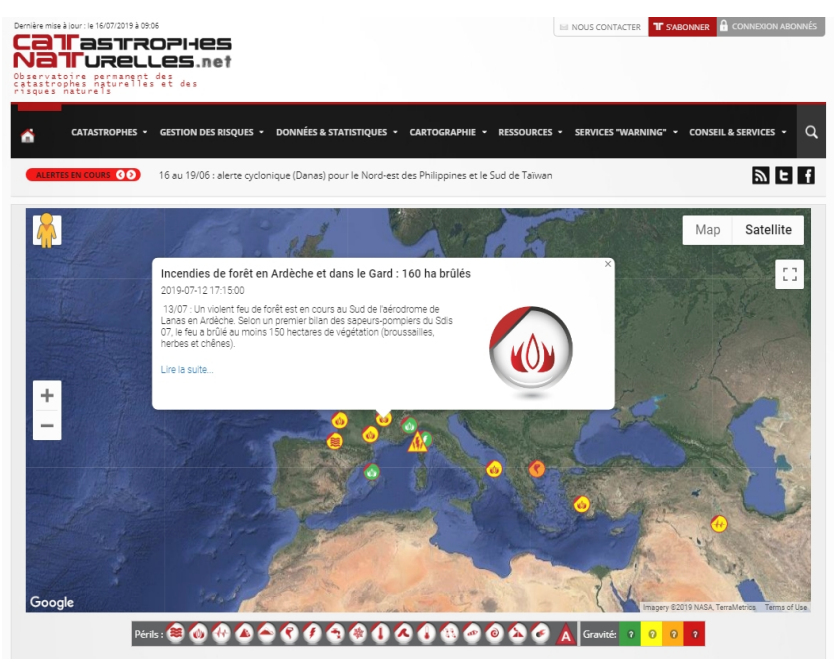

Figure 4. Figure catnat site web Interface 
4.1.2 TARIKI (tariki.dz): TARIKI is a governmental site web dedicated to traffic information in Algeria. This solution is based on open source software and platforms. Created and initiated by the "Gendarmerie Nationale" (police), it allows road users to learn about the road situation in real time, and is accessible through the various means of communication and information, such as PC, Laptop, Tablet, and smartphone. The Information is received from the Information and Coordination Center of the "Gendarmerie National", through the territorial groups of the 48 prefectures of the country.(TARIKI 2017)

"Tariki" also offers road users an interactive map that displays different useful information during their travels, including road conditions, possible and optimal routes, congestions, traffic jams and black spots.

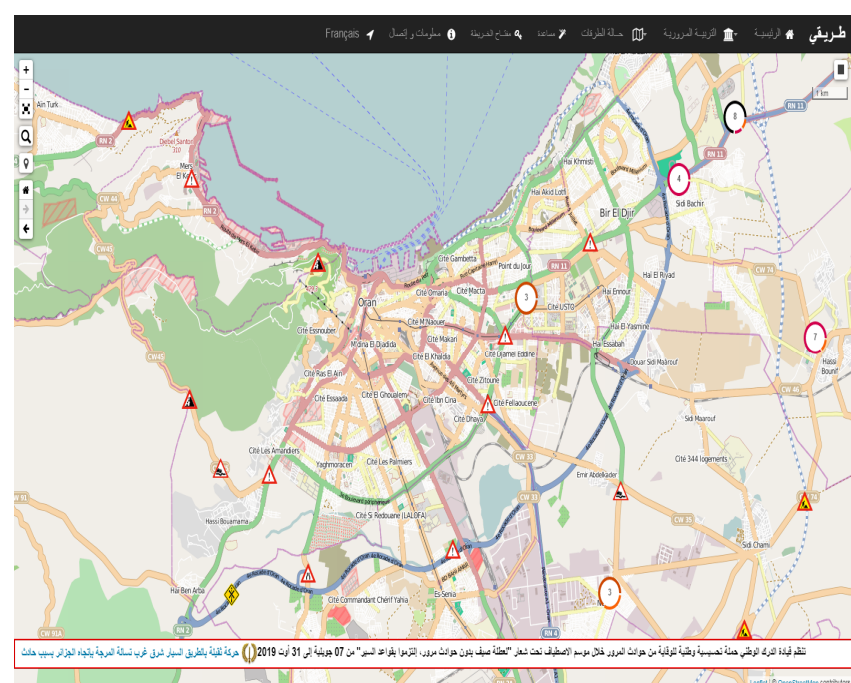

Figure 5. Figure TARIKI site web Interface

\subsection{Localization}

In the examples cited above, the citizen is not asked to provide data of the disaster, so we try to find the simplest way to involve him in the operation.

All contributions in our platform need a position, i.e. a point with coordinates and then give information on this place, but two problem arise: the first is if there is no GPS (global positioning system) signal as a blocked person who cannot display the coordinates $\mathrm{x}, \mathrm{y}$ of his position, the second if a person wants to share information on a point that he does not occupy (eyewitness, specialist, authority ...)

The accurate localization is essential in order to make it valuable for the rescue intervention, various approach exist for that:
4.2.1 Localisation by mobile devices: mobile devices allow this, but since GPS requires a line-of-sight to the satellites, it will be not suitable for indoor, so on the basis of wireless internet signals from WIFI access point, the localization problem can be solved, but drawbacks are the limitation to urban environment and also the missing of positional accuracy in the case of moving. (Doris 2013)

4.2.2 Localization by verbal descriptions: this method of defining a place via social networks (e.g. Facebook) remains practical mostly for people who have little knowledge of geolocalization, but the description cannot be converted to geographic information or be processed automatically.

4.2.3 Localization by map: the accuracy of the chosen place depends on the knowledge participants have about the area, and the scale of the map. That is why we prefer this type of positioning in our work, we will have better accuracy

\subsection{The Platform}

4.3.1 The concept: the process is summarized by choosing an event or disaster initiated by the administrator of the web site, in continuation the zone concerned appears in a OSM map, and the contributor specifies a place (point) and once the point is stung, the user has the opportunity to introduce information about the place: SOS, road closed, need help (water, doctor, blankets...), person stuck ...etc. these data will be recorded in the online database of the platform and then translated automatically into map symbols with information popups.

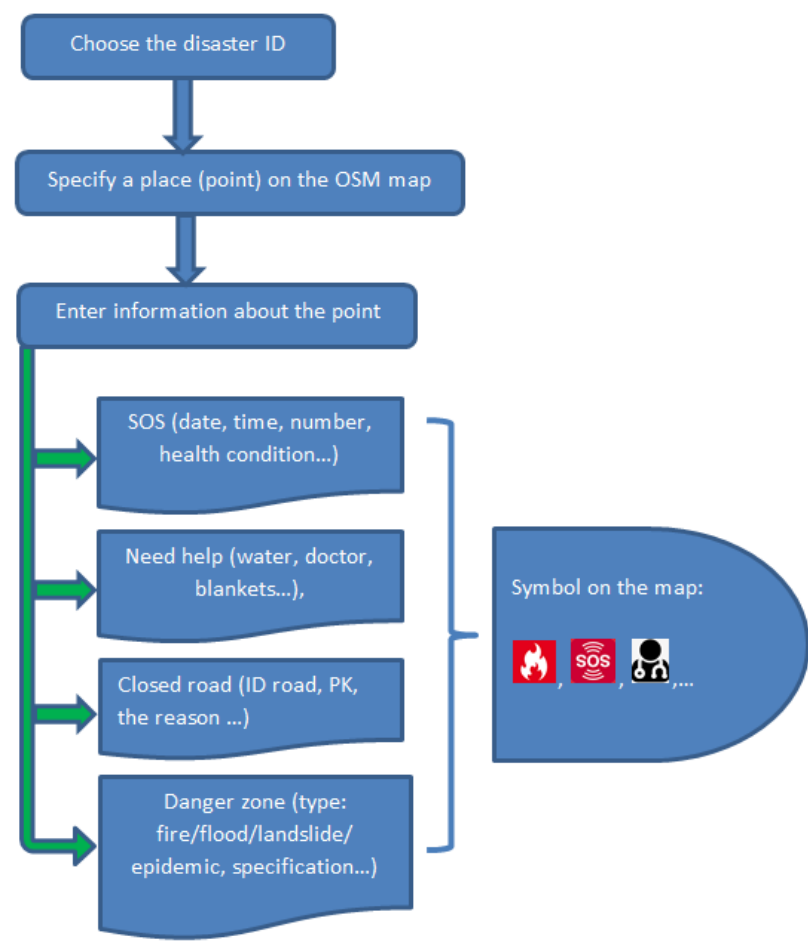

Figure 6. Figure Platform model

4.3.2 The tools: in additional of the OSM maps, the opensource OpenLayers library based on JavaScript can display map data in web browsers. It provides an API for building rich web-based geographic applications similar to Google Maps and Bing Maps. 
4.3.3 Data processing: here is the flow of information to the database and back to the display after treatment:

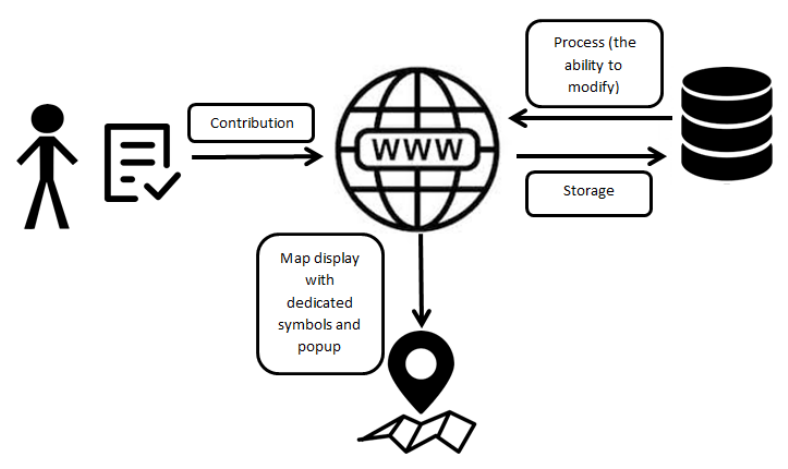

Figure 7. Figure data flow

The contributor goes to the platform, accesses to the link of the catastrophe which was created by the administrator, after choosing a place (point) he fills information on a form relating to the point and submit. The information will be saved in the database dedicated to the disaster, the administrator can modify at the request of the official organizations (they have the correct information). Then and from the database, the map will be enriched by symbols and popups.

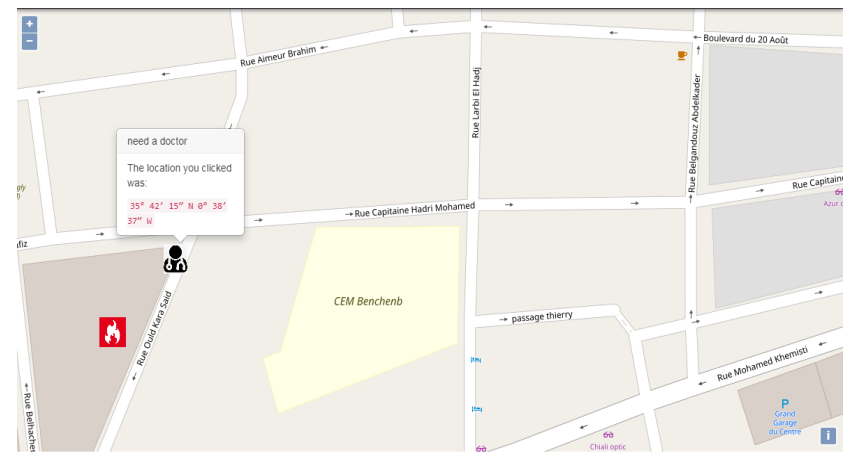

Figure 8 . Figure how the platform look

\section{CONCLUSION}

In this paper, we try to make people aware of the devastating consequences of natural disasters to initiate them to participate in exercises that aim to help themselves and offer support to others, these practices must be taught at school to the children (place description, rescue gesture, localization...). Concerning the OSM and information sharing, the principle remains interesting despite its defects (redundancy, bad intension) and even with the appearance of drones.

Technically this solution can be enriched by deep studies to define the most important fields of information to set up, and to find a way to eliminate or understand repeated information.

Other functionalities can appear on the platform such as: signaling of irregular events (prevention), management of aids coming from outside, and integrate advice and good practice during natural disaster (what to do).

\section{ACKNOWLEDGEMENTS (OPTIONAL)}

I want to thank my colleagues at the Space Technology Center.

\section{REFERENCES}

Bretmaps, (2019).Gaia Guadanoli, Le digital pour faire face aux catastrophes naturelles.Building Resilience Empowering Technology \& Maps. bretmaps.com (20 May 2019).

Yannick Manche, (2006). Analyse spatiale et mise en place de système d'information pour l'évaluation de la vulnérabilité des territoires de montagnes face aux risques naturels. tel.archivesouvertes.fr/tel-00077807

Jamal Jokar Arsanjani (2011). Assessing the Quality of OpenStreetMap Contributors together with their Contributions. AGILE 2013 - Leuven, May 14-17, 2013

Zielstra, D. \& Zipf, A. (2010): A Comparative Study of Proprietary Geodata and Volunteered Geographic

Information for Germany. AGILE 2010. Guimarães, Portugal.

Muki Haklay, How good is volunteered geographical information? A comparative study of OpenStreetMap and Ordnance Survey datasets, Environment and Planning B: Planning and Design, 37(4), pages 682-703, 2010.

Morgane LACROIX , Marc SOUVILLE (2014) Etudes Les facteurs influençant la prise de décision des Commandants des Opérations de Secours :Quels enjeux pour la formation ? ENSOSP, France https://dumas.ccsd.cnrs.fr/dumas00770075/document

CATastrophes NATurelles.net, Ubyrisk Consultants,2019 Accès en ligne à la base "BD Catnat", Saint-Martin-de-Laye , France catnat.net/donneesstats/bd-catnat

TARIKI, « Gendarmerie National », 2017, Minister of National Defense, Algeria tariki.dz/indexar.html

Doris Dransch, Joachim Fohringer, Kathrin Poser, Christian Lucas, 2013. Volunteered Geographic Information for Disaster Management, Citizen e-participation in urban governance : crowdsourcing and collaborative creativity. DOI: 10.4018/9781-4666-4169-3.ch007 